\title{
NI 70 ERPs could represent a logographic processing strategy in visual word recognition
}

\author{
Gregory Simon*1,2, Laurent Petit ${ }^{1}$, Christian Bernard ${ }^{2}$ and Mohamed Rebaï ${ }^{2}$
}

Address: ${ }^{1}$ Groupe d'Imagerie Neurofonctionnelle, UMR 6194, CNRS CEA, Universities of Caen \& Paris Descartes, GIP Cyceron, boulevard Henri Becquerel, 14074 Caen Cedex, France and '2Laboratoire Psychologie et Neurosciences de la Cognition (EA1780), University of Rouen, rue Lavoisier, 76821 Mont Saint Aignan Cedex, France

Email: Gregory Simon* - simon@cyceron.fr; Laurent Petit - lpetit@cyceron.fr; Christian Bernard - christian.bernard@univ-rouen.fr; Mohamed Rebaï - med.rebai@wanadoo.fr

* Corresponding author

Published: 23 April 2007

Behavioral and Brain Functions 2007, 3:21 doi:10.1186/1744-9081-3-21
Received: 16 January 2007

Accepted: 23 April 2007

This article is available from: http://www.behavioralandbrainfunctions.com/content/3/I/2I

(C) 2007 Simon et al; licensee BioMed Central Ltd.

This is an Open Access article distributed under the terms of the Creative Commons Attribution License (http://creativecommons.org/licenses/by/2.0), which permits unrestricted use, distribution, and reproduction in any medium, provided the original work is properly cited.

\begin{abstract}
Background: Occipito-temporal NI70 component represents the first step where face, object and word processing are discriminated along the ventral stream of the brain. NI70 leftward asymmetry observed during reading has been often associated to prelexical orthographic visual word form activation. However, some studies reported a lexical frequency effect for this component particularly during word repetition that appears in contradiction with this prelexical orthographic step. Here, we tested the hypothesis that under word repetition condition, discrimination between words would be operated on visual rather than orthographic basis. In this case, NI70 activity may correspond to a logographic processing where a word is processed as a whole.
\end{abstract}

Methods: To test such an assumption, frequent words, infrequent words and pseudowords were presented to the subjects that had to complete a visual lexical decision task. Different repetition conditions were defined I - weak repetition, 2 - massive repetition and 3-massive repetition with font alternation. This last condition was designed to change visual word shape during repetition and therefore to interfere with a possible visual strategy during word recognition.

Results: Behavioral data showed an important frequency effect for the weak repetition condition, a lower but significant frequency effect for massive repetition, and no frequency effect for the changing font repetition. Moreover alternating font repetitions slowed subject's responses in comparison to "simple" massive repetition.

ERPs results evidenced larger NI70 amplitude in the left hemisphere for frequent than both infrequent words and pseudowords during massive repetition. Moreover, when words were repeated with different fonts this NI70 effect was not present, suggesting a visual locus for such a NI 70 frequency effect.

Conclusion: NI70 represents an important step in visual word recognition, consisting probably in a prelexical orthographic processing. But during the reading of very frequent words or after a massive repetition of a word, it could represent a more holistic process where words are processed as a global visual pattern. 


\section{Background}

Event-related potential N170 is a negative occipito-temporal component peaking around $170 \mathrm{~ms}$ after presentation of visual stimulus such as face, object or word. Despite its early latency, recent advances suggest that this component represents an important stage of processing in recognition of a visual pattern. The first well-established proofs were provided by comparing recognition processes involved in faces and objects. Numerous studies demonstrated larger N170 amplitudes for face than object and evidenced that only face's rotation affected N170 amplitude and latency [1-3]. Those differences were interpreted as the existence of a face-specific encoding, but recent works evidenced that N170 inversion effect can also occur during the processing of Greebles (a class of fictional objects) when subjects were trained to recognize them [4]. This last result contradicted the face-specific processing hypothesis and raised the question of expertise for this component. But more important, Bentin and Golland [5] suggested that face $\mathrm{N} 170$ associated with extrastriate visual mechanisms is modulated by top-down processes, because the same stimuli can elicit different amplitudes as a function of subject's knowledge about these stimuli (see also Jemel and colleagues [6]).

The N170 component appears then as a main step in visual pattern extraction and recognition for face and object but the question of its specificity is still debated as well as its functional signification during word reading. Only one study compared directly N170 elicited by faces, objects and words. This component was right lateralized for faces, smaller and bilateral for objects such as cars, and strongly left lateralized for printed words [7]. According to Vigneau and colleagues, the hemispheric lateralization may be a better marker of the functional brain specialization than some increased activity at a given anatomical location [8] and the N170 component represents the earliest left lateralized component during word recognition. As a matter of fact, in the domain of visual word recognition, both ERP and MEG experimental data comparing the processing of orthographic stimuli with that of pseudoletter strings (e.g., false font, ASCII symbols,...) reported a greater N170 leftward negativity for orthographic stimuli [9-12]. Those modulations were interpreted as related to the expertise for letters or well-ordered letter strings and suggest the existence of an orthographic encoding stage for N170 in the left hemisphere. In addition, a combined fMRI and ERP study evidenced a positive correlation between the amplitude of the late part of N170 and the metabolic activity in the visual word form area (VWFA) [13]. This left fusiform area, as well as the N170 component, may be dedicated to prelexical letter processing because of similar activations usually reported for words of different semantic categories and pseudowords $[8,9,14]$.
However in the literature, some studies reported a N170 word frequency effect that was often interpreted as a lexical access modulation. This frequency effect and this interpretation are clearly in disagreement with the hypothesis of a prelexical orthographic processing for N170 elicited by words. But in these studies, words were irregular/lexical ambiguous [15,16] or presented tachistoscopically [17], some parameters that may have an impact on orthographic encoding. Interestingly, MEG studies of Assadollahi and Pulvermuller [18,19] evidenced a word frequency effect close to the N170 latency, using repeated stimuli. Simon and colleagues [11] also obtained a N170 word frequency effect during a lexical decision task but only when a massive repetition was used. In this last experiment, repeated frequent words elicited a larger N170 amplitude than infrequent ones, the same effect as the face familiarity found during massive repetition by Caharel and colleagues $[20,21]$. We can thus suppose that repetition plays an important role in N170 word frequency effect.

As a matter of fact we decided in this study to investigate the interaction between the word lexical frequency and the repetition of stimuli on N170 component. Indeed the repetition can be used in experimental paradigm in order to "artificially" modulate the lexical frequency of words. One may argue that the N170 elicited by massively repeated words may represent a different processing that the ones elicited by words presented in "standard" conditions. But if we consider that the N170 is usually associated to orthographic encoding - at least for its early part (i.e. letter recognition), what kind of processing favors repetition? The more coherent interpretation would be that under word repetition effect, discrimination between stimuli would be operated on visual rather than orthographic basis. In this case, such a processing may be assimilated to a logographic stage [22] in which words are not recognized as a string of letters but rather as a whole visual pattern (see also, [23]), applying holistic processes as in face perception. The MEG study of Tarkiainen and colleagues evidenced that even though the hemispheric balance was different around $150 \mathrm{~ms}$ for face and letterstring, the activated areas within the inferior occipito-temporal cortex were very close to each other [24].

In fact, the understanding of whether the visual word recognition is assumed only on the basis of letters or with other pertinent sources such as global visual pattern, is an important and recurrent question concerning alphabetic languages [25]. To test the effects of word perceptual familiarity and therefore indirectly the hypothesis of a logographic processing in adults, most paradigms created subtle but significant perceptive deformations of the stimuli in order to estimate their impact on the visual word recognition. As a matter of fact, the modification of the 
word's visual shape is supposed to disrupt the logographic processing. Numerous perceptual transformations have been used, such as contrast manipulation [26] or cAsE MixIng [25,27-30]. But these experiments produced heterogeneous behavioral results that are difficult to interpret. According to a fMRI study of Polk and Farah [31], no significant difference in activation was obtained comparing pure-case and alternating-case words in the left VWFA. This result suggests that the response of this area and therefore probably the N170 amplitude would not be modulated by perceptual familiarity. In this case, it appears difficult to explain the N170 word frequency effect evidenced in some studies.

We performed the present study in order to investigate the word frequency effect on N170 and to test the hypothesis of the emergence of a visual/logographic process during a massive repetition. EEG was recorded continuously as subjects performed a lexical decision task with three mixed repetition modalities. This task was chosen in order to ensure lexical access and therefore behavioral word frequency effects. The first repetition modality consisted in the presentation of lists of frequent words, infrequent words and pseudowords presented only twice (weak repetition). The second repetition condition consisted in 100 repetitions for each type of stimulus (massive repetitions). The third was the same that the previous but stimuli were repeated with different fonts (alternating font repetitions). The font manipulation was chosen instead of a case mixing because we estimated that it allows to disrupt the logographic processing without an important disturbance of word recognition when simple fonts are used. The hypothesis was that if alternating case fonts led to a disappearance of the N170 frequency effect despite of a massive repetition, it would attest for the use of a visual/ logographic strategy in the word recognition. Moreover, in order to assess the evolution of the repetition effect through the time, we contrasted electrophysiological data obtained at the beginning of the experiment with the ones of the end of session.

\section{Methods \\ Participants}

Twenty-eight literate adults (14 men and 14 women), aged 20-30 years, with no history of neurological disease or learning impairment, participated to the behavioral study. Ten of them ( 5 men and 5 women) were then selected for ERPs. All of the subjects had normal or corrected-to-normal vision, were right-handed (Edinburgh test [32]), and had no previous history of neuropsychiatric disorders.

\section{Stimuli}

The stimuli consisted of frequent words, infrequent words and pseudowords presented according to three condi- tions: 1 - weak repetitions, 2 - massively repeated items and 3 - massively repeated items with different fonts. For the weak repetitions condition, lists of 50 frequent words, 50 infrequent words and 50 pseudowords were constituted. Lexical frequencies of the words were assessed with the Brulex French database [33] and were significantly different $(\mathrm{p}<.001)$ between the frequent and infrequent lists (mean: 11.054 and 160 per 100 million respectively). Moreover, in both lists, the words had an identical mean of 7 letters, were constituted of 2 syllables, had a late orthographic uniqueness point and few orthographic neighbors. The 50 pseudowords used for weak repetitions conditions were matched with word's lists for syllables and number of letters. For massively repeated items condition, one frequent word, one infrequent word and one pseudoword were selected. All were unused in weak repetition condition but were chosen to match to the characteristics of the lists. For the massively repeated condition with different fonts, three new items were chosen as previously. Twenty five different fonts were then applied to these three stimuli (figure 1). Fifty different fonts were initially used, but on the basis of pre-experimental behavioral data, the fonts that disrupted too much word recognition were removed and only 25 from them were finally selected.

\section{Procedure}

The subjects were comfortably seated in the dark at a distance of $60 \mathrm{~cm}$ from a computer screen. The stimuli were white on a dark background with a visual angle subtending $2^{\circ}$ and lasted $1 \mathrm{~s}$, followed by a blank period lasting between 900 and $1100 \mathrm{~ms}$ during which the subjects stared at a fixation point. The subjects had to decide whether the stimulus was a word or not (lexical decision) by pressing one of two keys with their right hand.

The acquisition of behavioral and ERP data was separated by several weeks. Both behavioral and ERPs experiments were preceded by a training session.

\section{MUSIQUE MUSIQUE MDSUCDB MUSIQUE MUSGQZE AUNIQUE mUSIOUE TTV맴E MUSIQUE MUSTaOE MUSIOUE MUSTOUE MUSIOLIE MUSIQUE MUSIQUE MOSIQUE' MUSISUE MUSIRUE MUSIQUE MUSIQLE MUSIQUE MUSIQUF, MUISIOUIE MUSLQUE MUSIQUE}

Figure I

Fonts used for repetition with font alternation condition. 


\section{Behavioral study}

For each participant, 20 frequent words, 20 infrequent words and 20 pseudowords were randomly selected among lists of 50 stimuli of the weak repetition condition. In the same way, 20 different fonts were selected among the 25 possibilities and were applied to the three stimuli for the repetition with different fonts condition. Stimuli of the massively repeated condition were repeated 20 times (see table 1). Presentation of all stimuli was mixed and no stimulus from a same condition was presented consecutively.

A 3 modalities stimulus factor (frequent words/infrequent words/pseudowords) ANOVA was performed for each repetition condition on reaction times obtained for correct answers. A supplementary analysis was conducted in order to assess font alternation effects. This last analysis was applied only to massively repeated stimuli with and without alternating font repetitions with a 2 modalities font alternation factor (with/without) $\times 3$ stimulus factor (frequent words/infrequent words/pseudowords) ANOVA.

\section{ERP study}

During EEG acquisition, all 50 frequent words, 50 infrequent words and 50 pseudowords were presented twice in the weak repetition condition and repeated 100 times in the massive repetition condition. For the alternating font repetition condition, each font was presented 4 times (table 1).

In order to avoid the recording of motor-related ERPs (see for example [32]), subjects responded to lexical decision only after hearing a beep sound announcing the end of word presentation during EEG acquisition (figure 2).

The EEG was recorded with 32 tin electrodes (electrocaps) from FP1, F7, F3, C3, T3, CP3, TP7, T5, PO5, PO3, P3, O1, $\mathrm{XO} 1, \mathrm{FP} 2, \mathrm{~F} 8, \mathrm{~F} 4, \mathrm{C} 4, \mathrm{~T} 4, \mathrm{CP} 4, \mathrm{TP} 8, \mathrm{~T} 6, \mathrm{PO} 6, \mathrm{PO} 4, \mathrm{P} 4, \mathrm{O} 2$, $\mathrm{XO} 2, \mathrm{Fz}, \mathrm{Cz}, \mathrm{Cpz}, \mathrm{Pz}, \mathrm{Poz}$, and $\mathrm{Oz}$ sites distributed according to the 10-20 system. During acquisition, each electrode was referred to $\mathrm{Cz}$. Electrode resistance was kept under $5 \mathrm{k} \Omega$. The EEG was amplified, digitized at a rate of
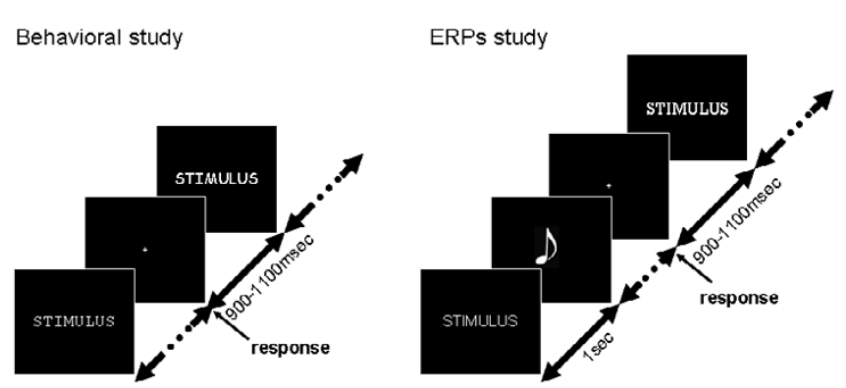

Figure 2

Design of behavioral and ERPs studies.

$256 \mathrm{~Hz}$, filtered (band-pass $0.1 \mathrm{~Hz}-100 \mathrm{~Hz}$ ), and stored on the Deltamed ${ }^{\mathrm{TM}}$ software system.

The EEGs were averaged with a multi-electrode reference [34] composed of F7, F3, C3, T3, CP3, TP7, T5, P3, F8, F4, C4, T4, CP4, TP8, T6, P4, Fz, Cz, Cpz, and Pz sites. These electrode sites were chosen in order to obtain a uniform distribution on the scalp. Frequencies higher than $48 \mathrm{~Hz}$ were rejected. The baseline was calculated as the mean voltage during the $250 \mathrm{~ms}$ preceding the stimuli. Approximately $5 \%$ of the trials were excluded because of ocular artifacts, defined by amplitudes greater than $100 \mu \mathrm{V}$ at FP1 and FP2 electrodes.

Because of the great differences between the repetition conditions, we performed statistical analyses separately for weak repetition condition, massive repetition, and massive repetition with font alternation. Moreover, we averaged EEG for the 50 first presentations and the 50 last presentations separately for these 3 conditions in order to have a better overview of the repetition effects.

Because of the goal of the study, we focused on the N170 component. Statistical analyses were performed on mean amplitudes collected between 140 - 280 ms for occipital (O1, XO1, O2, XO2) and posterior temporal electrodes (T5, PO5, T6, PO6) with a 2 average epoch factor (50 first stimuli/50 last stimuli) $\times 3$ stimulus (frequent words/

Table I: Repetition conditions for behavioral and ERP study

\begin{tabular}{|c|c|c|c|}
\hline & Weak repetition & Massive repetition & Alternating fonts repetition \\
\hline \multirow[t]{3}{*}{ Behavioral study } & 20 frequent words & I frequent word $\times 20$ & I frequent word $\times 20$ different fonts \\
\hline & 20 infrequent words & I infrequent word $\times 20$ & I infrequent word $\times 20$ different fonts \\
\hline & 20 pseudowords & I pseudoword $\times 20$ & I pseudoword $\times 20$ different fonts \\
\hline \multirow[t]{3}{*}{ ERP study } & 50 frequent words $\times 2$ & I frequent word $\times 100$ & I frequent word $\times 25$ different fonts $\times 4$ \\
\hline & 50 infrequent words $\times 2$ & 1 infrequent word $\times 100$ & I infrequent word $\times 25$ different fonts $\times 4$ \\
\hline & 50 pseudowords $\times 2$ & I pseudoword $\times 100$ & I pseudoword $\times 25$ different fonts $\times 4$ \\
\hline
\end{tabular}


infrequent words/pseudowords) $\times 2$ hemispheres (left/ right) $\times 2$ electrodes ANOVA.

When necessary, Tukey HSD post-hoc analyses were conducted.

\section{Results}

\section{Behavioral data}

For the weak repetition, a stimulus main effect was found on RTs $\left(\mathrm{F}_{2,54}=70.53, \mathrm{p}<.001\right)$, as frequent words $(\mathrm{m}=$ $602 \mathrm{~ms} ; \mathrm{SD}=78$ ) elicited faster responses than infrequent ones $(\mathrm{m}=679 \mathrm{~ms} ; \mathrm{SD}=103)$ and pseudowords $(\mathrm{m}=776$ $\mathrm{ms} ; \mathrm{SD}=133$ ) (figure 3).

For massively repeated stimuli, a similar but attenuated pattern was obtained $\left(\mathrm{F}_{2,54}=170.15, \mathrm{p}<.001\right)$, responses to frequent $(\mathrm{m}=538 \mathrm{~ms}$; $\mathrm{SD}=77)$ being faster than infrequent words $(\mathrm{m}=562 \mathrm{~ms} ; \mathrm{SD}=79.82)$ and pseudowords $(\mathrm{m}=676 \mathrm{~ms} ; \mathrm{SD}=66)$ (figure 3$)$.

Concerning the alternating font repetitions, a stimulus main effect was also evidenced $\left(\mathrm{F}_{2.54}=139.83, \mathrm{p}<.001\right)$. However, post-hoc comparisons indicated that frequent word $(568 \mathrm{~ms} \pm 74)$ didn't differ significantly from infrequent ones $(\mathrm{m}=586 \mathrm{~ms} ; \mathrm{SD}=81)$ whereas these two

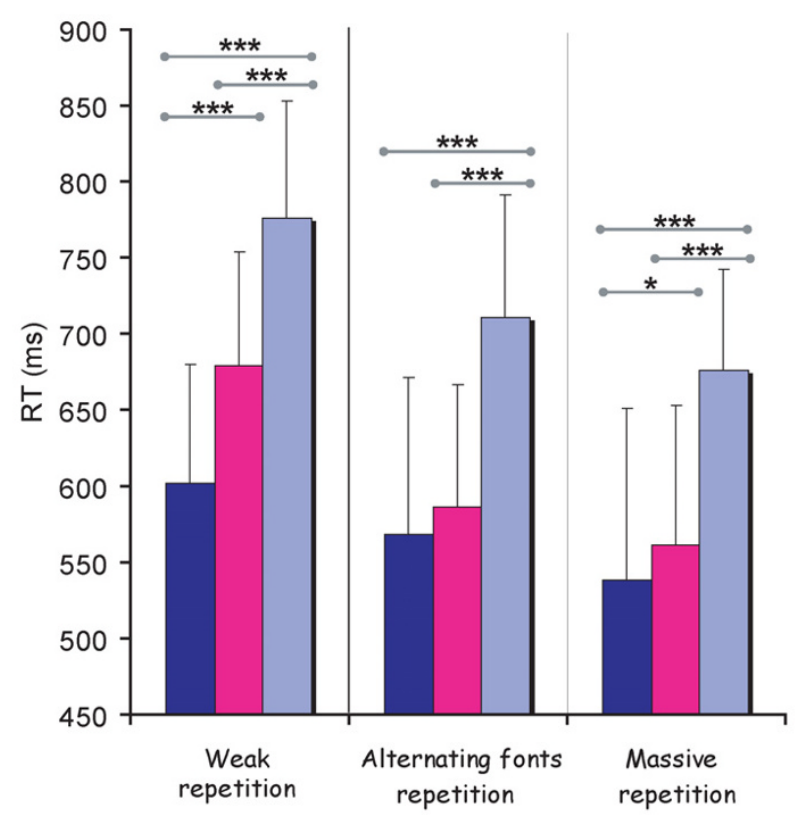

- Frequent words $\square$ Infrequent words $\square$ Pseudowords

\section{Figure 3}

Stimulus and repetition type effects on RTs. Legends. ***: $\mathrm{p}<.001 ; *$ : $<.05$ types of words elicited faster responses than the pseudoword $(\mathrm{m}=711 \mathrm{~ms} ; \mathrm{SD}=92)$ (figure 3$)$.

The comparison between massive repetition with and without alternating font evidenced a main effect of font alternation $\left(\mathrm{F}_{1,27}=48.48, \mathrm{p}<.001\right)$. Subjects responded faster after massive repetition $(\mathrm{m}=592 \mathrm{~ms} ; \mathrm{SD}=95)$ than alternating font condition $(\mathrm{m}=622 \mathrm{~ms} ; \mathrm{SD}=103)$. A stimulus effect $\left(\mathrm{F}_{2,54}=282.65, \mathrm{p}<.001\right)$ was also found as previously reported. The interaction repetition $\times$ stimulus was not significant.

\section{NI70 electrophysiological data}

Because of the great number of repetitions occurred during the ERP acquisition, the differences between the first 50 presentations and the last 50 were assessed in order to estimate the evolution of the repetition effect. In the weak repetition condition, the repetition effect consisted in the comparison of the first presentation of 50 stimuli contrasted to the second presentation of the same 50 stimuli. In massive repetition condition, the 50 first presentations of a unique stimulus were compared to the 50 last of the same unique stimulus. In alternating font repetitions condition, the 50 first presentations of a unique stimulus presented with different fonts were compared to the 50 last presentations of the same condition.

\section{Weak repetition}

Analysis comparing different stimuli of the lists and the repetition (the difference between the first and the second presentation) of these stimuli evidenced a main effect of hemisphere at temporal $\left(\mathrm{F}_{1,9}=5.41, \mathrm{p}<.05\right)$ and occipital electrodes $\left(\mathrm{F}_{1,9}=5.72, \mathrm{p}<.05\right)$, as the negativity was larger on the left side.

At temporal locations (figure 4A), an interaction between the stimulus type, the repetition and the hemisphere was evidenced $\left(\mathrm{F}_{2,18}=5.48, \mathrm{p}<.05\right)$. It corresponded to a larger negativity for the second presentation in comparison to the first one that was specific to frequent words (figure 4B) and observed only in left hemisphere ( $<$.001). Despite this strong repetition effect on frequent words, post-hoc analysis evidenced no significant word frequency effect on N170.

At occipital electrodes, an interaction was obtained between repetition and electrode $\left(\mathrm{F}_{3,27}=3.00, \mathrm{p}<.05\right)$, due to a larger negativity between the first and the second presentation of the stimuli that was greater for $\mathrm{O} 1$ and $\mathrm{O} 2$ locations than $\mathrm{XO} 1$ and $\mathrm{XO} 2$ ones.

\section{Massively repeated stimuli}

Although words and pseudoword were repeated 100 times, an hemispheric main effect was also evidenced in 
A.

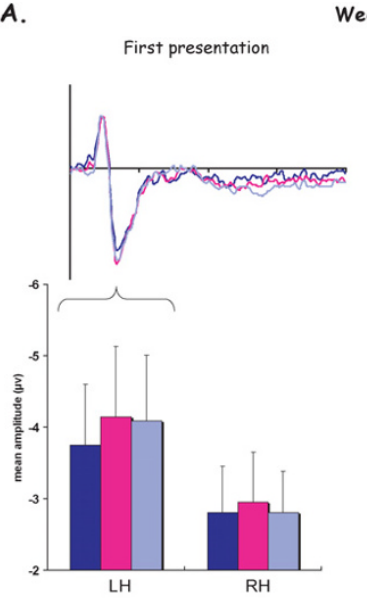

Weak repetition

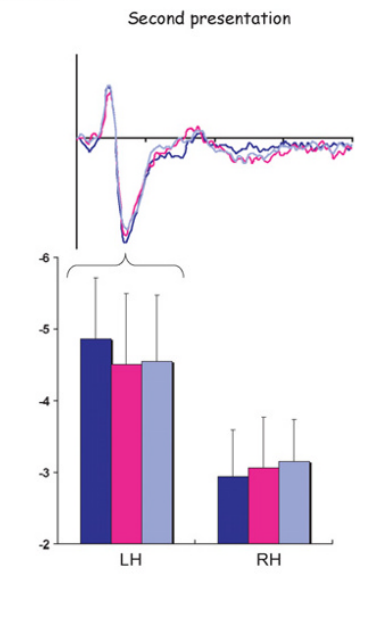

B.

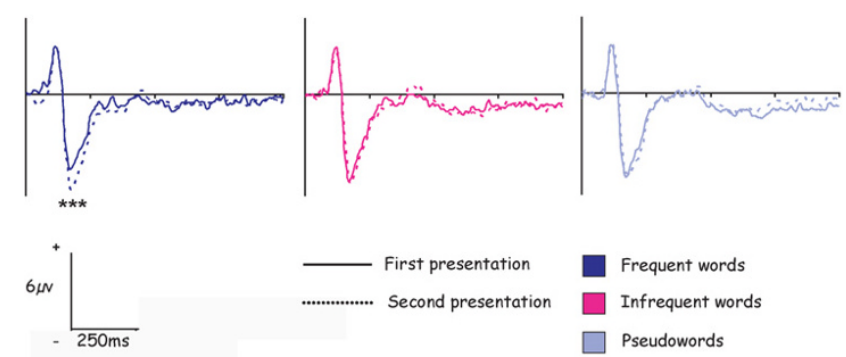

Figure 4

ERPs results for the weak repetition. A. Histograms represent NI70 mean amplitudes averaged for T5-PO5 temporal electrodes at the left (LH) and T6-PO6 at the right hemisphere $(\mathrm{RH})$. B. ERPs obtained for the first and the second presentation of the three lists of 50 stimuli. All ERPs illustrations corresponded to T5 electrode. temporal $\left(\mathrm{F}_{1,9}=7.59, \mathrm{p}<.05\right)$ and occipital $\left(\mathrm{F}_{1,9}=7.28, \mathrm{p}\right.$ $<.05)$ electrodes.

At temporal location (figure 5), an interaction between stimulus and hemisphere $\left(\mathrm{F}_{2,18}=4.69, \mathrm{p}<.05\right)$ was obtained, frequent word eliciting larger negativity that infrequent word and pseudoword but only in the left hemisphere $(\mathrm{p}<.01)$. An interaction stimulus $\times$ repetition $\times$ hemisphere $\times$ electrode was also evidenced $\left(\mathrm{F}_{2,18}=4.69\right.$, $\mathrm{p}<.05)$, word frequency effect being significant for all left temporal electrodes (T5 and PO5) during the 50 last presentations whereas this frequency effect was present only at T5 electrode for the 50 first presentations.

ERPs obtained at occipital electrodes were not modulated significantly by stimulus type or repetition.
A.

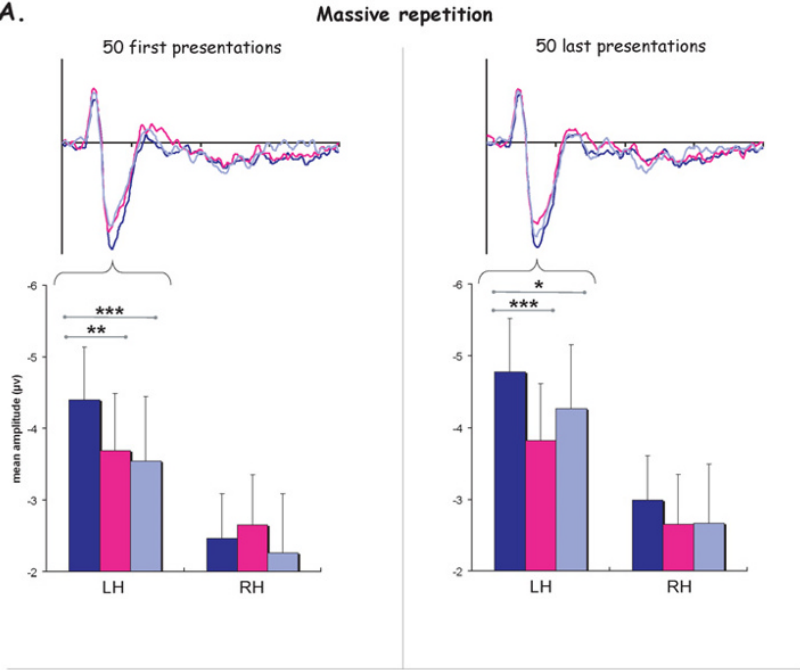

B.

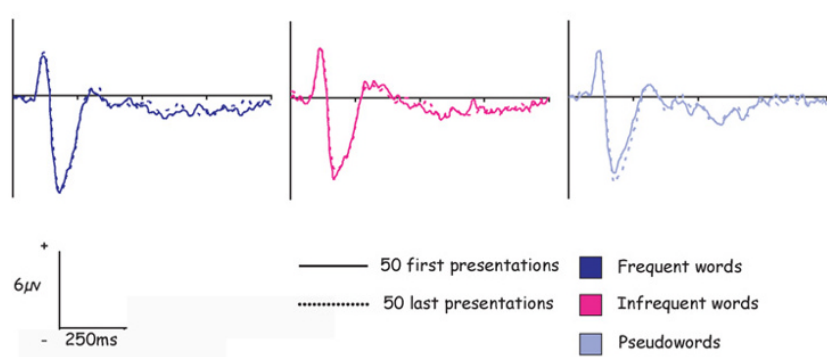

Figure 5

ERPs results for the massively repeated stimuli. A. Histograms represent NI70 mean amplitudes averaged for T5-PO5 temporal electrodes at the left (LH) and T6-PO6 at the right hemisphere (RH). B. ERPs obtained for the 50 first and the 50 last presentations of the three massively repeated stimuli. All ERPs illustrations corresponded to T5 electrode.

\section{Alternating font repetitions}

At temporal location, in addition to an hemispheric main effect $\left(\mathrm{F}_{1,9}=5.67, \mathrm{p}<.05\right)$, an interaction stimulus $\times$ repetition $\left(\mathrm{F}_{2,18}=4.55, \mathrm{p}<.05\right)$ was evidenced. Indeed, contrary to massive repetition condition, the $\mathrm{N} 170$ elicited during the 50 first repetitions with alternated fonts was not modulated by stimulus properties (figure 6). However during the 50 last repetitions, frequent words elicited larger negativity than pseudowords in left $(\mathrm{p}<.05)$ and right hemisphere $(\mathrm{p}<.05)$. Although frequent words generated larger amplitudes than infrequent ones, these differences didn't reach significance.

At occipital electrodes, only hemisphere $\left(\mathrm{F}_{1,9}=9.93, \mathrm{p}<\right.$ $.05)$ and electrode $\left(\mathrm{F}_{3,27}=3.00, \mathrm{p}<.05\right)$ main effects were significant. 
A.

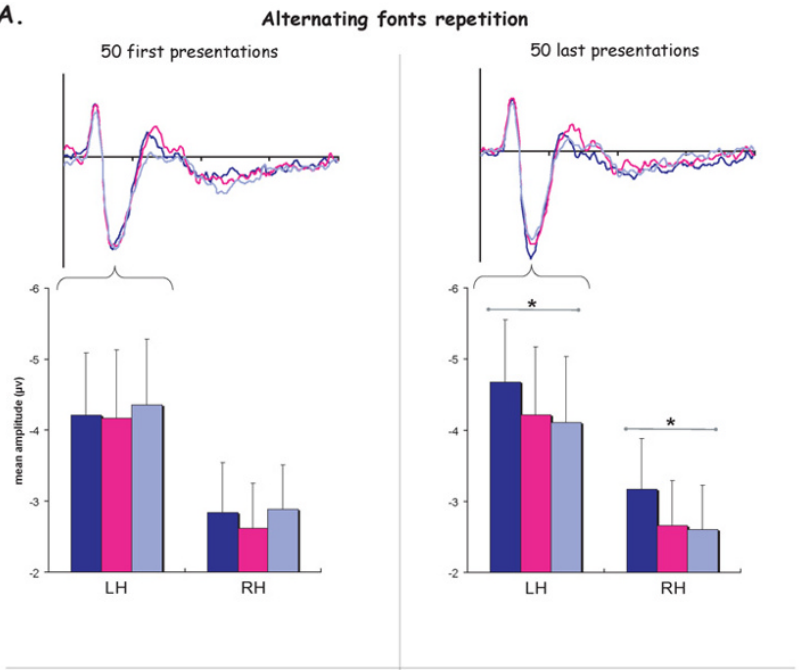

B.

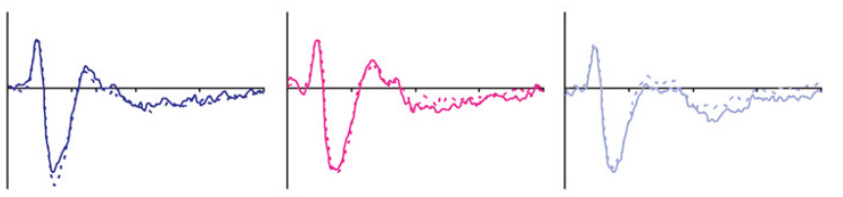

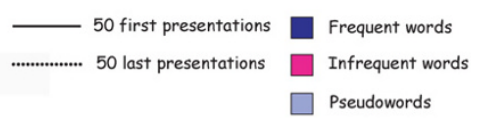

Figure 6

ERPs results for the alternating fonts massive repetition. A. Histograms represent NI 70 mean amplitudes averaged for T5-PO5 temporal electrodes at the left (LH) and T6-PO6 at the right hemisphere (RH). B. ERPs obtained for the 50 first and the 50 last presentations of the three stimuli repeated with different fonts. All ERPs illustrations corresponded to T5 electrode.

\section{Discussion}

\section{Behavioral data}

We obtained a strong frequency effect in the case of weak repetition, frequent words eliciting faster RTs than infrequent ones (mean difference $=77 \mathrm{~ms}$ ). This corresponds to the classical behavioral frequency effect obtained in lexical decision task well documented in literature [35-37]. Although the difference between frequent and infrequent words was not considerable in the massive repetition condition (mean difference $=24 \mathrm{~ms}$ ), it remains significant. On the contrary, no frequency effect was evidenced when words were repeated with different fonts.

In fact, the comparison between massive repetition with and without font change demonstrated that the visual modifications of the word's shape minored repetition effects, with faster RTs for stimuli repeated without font modifications. Alterations of the shape of letters (changing fonts) slowed down the word recognition and attenuated the faster responses observed under a massive repetition, as described for case mixing [27,29]. These behavioral data are thus in agreement with the hypothesis that subjects adopt a visual discrimination strategy during identification of repetitive verbal stimuli.

This last assumption couldn't be assessed only on the basis of RTs examination. RTs represent a global view about the sum of the sensory and cognitive processes involved in the lexical decision task and the font alternation effect could occur at different stages of processing. ERPs results allowed us to study one temporal window about these stages.

\section{Electrophysiological data}

Discrepancies exist between behavioral and ERPs data. However RTs represent the final step of a sum of process and frequency effect as well as repetition effect can occur at multiple levels. Because of the goal of this study our electrophysiological investigations focused only on an early component: the N170.

The results obtained for the weak repetition condition indicated that the N170 was not directly modulated by the word frequency. However, they evidenced a strong repetition effect specific to the frequent words, one repetition several minutes after the first presentation of the stimulus being enough to increase the negativity.

Most of fMRI works studying repetition effects reported a "suppression effect" consisting in a decrease of the signal in brain regions after the repetition of words [38] as well as faces [39]. This decrease of activity during the repetition was associated to a N400 repetition effect in electrophysiological studies $[37,40-44]$. On the contrary, our results demonstrated an early effect of the repetition that consisted in an increase of the amplitude for repeated stimuli. In fact these results are in agreement with the MEG study conducted by Dhond and colleagues [40] that evidenced that the earliest significant repetition effect during a paradigm of word stems generation appeared in the left posteroventral temporal cortex (centered in the lateral occipito-temporal sulcus) around $200 \mathrm{~ms}$ post-stimulus. As in the present study, they obtained a larger activation for repeated word stems in comparison to new word stems. According to Dhong and colleagues [45], when the repetition occurred 40 minutes after the stimulus presentation, then the repetition effect appeared only after 500 ms post-stimulus. Thus, the increase of the N170 amplitude during the repetition seems to be more linked to perceptive or lexicosemantic processes than long-term memory. 
Under massive repetition condition, we observed a frequency effect for the N170, replicating results obtained in a previous study with different subjects and stimuli [11]. The modulation of the N170 amplitude by the word frequency under a massive repetition seems thus to be a robust effect. With 50 non-immediate repetitions, a word frequency effect appeared, a frequent word eliciting greater negativity than an infrequent word and a pseudoword. This effect was observed in the temporal electrodes and not in the occipital ones and was present only in the left hemisphere. In addition, although this word frequency effect occurs for the 50 first and the 50 last repetitions, it appeared more wide-spread at the temporal sites for the last ones, suggesting a cumulative effect.

These results could explain why some studies obtained a N170 word frequency effect while others did not. Indeed, MEG studies of Assadollahi and Pulvermuller $[18,19]$ evidenced such a frequency effect at similar latencies of the N170 during a lexical decision using repeated stimuli. For the face, a similar N170 face familiarity effect was found during a massive repetition by Caharel and colleagues [20]. Therefore, the repetition seems to be a crucial element to observe a N170 word frequency effect and more generally a familiarity effect. This effect is probably also modulated by the task as revealed by a fMRI study of Henson and colleagues [39] with faces' stimuli.

The present results evidenced that some left temporal areas may produce more activity for words often encountered. However, this word repetition/frequency effect would not be consecutive to the VWFA activity alone. According to a fMRI study of Dehaene and colleagues [46], priming elicited reduction of activity in this area and this repetition effect was not modulated by letter case manipulation. These modulations of VWFA activity appear in contradiction with our results. We can hypothesize the existence of an early part of N170 component dedicated to a letter - visual pattern extraction whereas the late part corresponds to the VWFA involvement and to a more abstract representation of letters. These two processes would interact in a complex manner but the present word frequency/repetition effect would be related to the first stage of N170 component.

When alternating the font through a massive repetition, there was no difference between the frequent and infrequent words during the first 50 presentations in contrast to a "simple" massive repetition. This result suggests that the N170 frequency effect under a massive repetition has probably a perceptual source. This interpretation is strengthened by the study of Tanaka and Curran about object expertise because they support the view that enhanced N170 is probably the direct result of perceptual learning [47]. For the 50 last repetitions, we observed an increase of the N170 amplitude for the frequent word but not sufficient to evidence a significant frequency effect. However we obtained a difference between frequent words and pseudowords. We can thus assume that if we choose a greater number of stimulus exposures, the word frequency effect would be significant.

In fact our data can be interpreted according to several theoretical frameworks that we address thereafter.

\section{The magnocellular vs parvocellular hypothesis}

Whereas numerous models of visual word recognition postulate the existence of two pathways in reading such as a lexical route and a second one applying grapheme-phoneme conversion rules in order to explain word frequency effect $[48,49]$, our data suggest a more visual-basis effect. This effect may be explained by a parvo/magnocellular modulation in the visual word recognition. For example, according to Allen and colleagues [50], a word can be visually recognized either from its letter encoding or from its specific spatial frequency. The "letter-by-letter" route is slow, corresponding to the parvocellular pathway, as opposed to the faster holistic magnocellular system. In this model, familiar words may be identified by a global mode and infrequent words by a letter-by-letter analytic mode. A differential involvement of magno- and parvocellular pathway can probably modulate the N170, because a study of Torriente and colleagues [51] showed greater N170 amplitudes when subjects detected movements relative to colors of bars.

Moreover although very conflictual, some data suggested a link between magnocellular system impairment and developpemental dyslexia [52]. According to Vidyasagar [53], the interaction of the parvo and magnocellular system would play a crucial role in the early visual analysis of words and reading. In the light of these results, the larger amplitudes for frequent than infrequent words in the present study may correspond to the greater involvement of the magnocellular pathway at a logographic/holistic stage.

The absence of difference between the frequent and infrequent words during the first 50 repetitions with fonts mixing is also in agreement with this interpretation because the letter shape modification is more able to disrupt the fast magno- than parvocellular pathway. But how can we explain that this frequency effect appeared only during massive repetition? We can assume that these results are due to a threshold effect. Indeed, it is possible that very frequent words such as articles or prepositions generate holistic processing without a repetition, but because of the weak number of those stimuli and their great heterogeneity, ERPs technique doesn't allow us to test such a hypothesis. 


\section{Global vs local processing}

Electrophysiological literature contrasting both local (e.g. letter level) and global (e.g. whole word form) processing evidenced conflictual results. Some studies have found larger amplitudes during local than global processing for the P100 but not for the N170 component [54,55]. Some others have found such effects at longer latencies [56,57] or on the N170 but in an opposite manner to ours, i.e. an enhanced negativity for the local processing [58,59]. These discrepancies among those previous results but also with the present data may be explained by the stimuli and the tasks used. In these studies, visual objects composed of local elements that are spatially arranged to form a global shape were presented to subjects who had to pronounce on either local or global attributes. Such a global/ local task is very different from the lexical decision that we used, because in the former one's attention is explicitly directed to local or global attributes (goal-directed attention) whereas in the later global/local processing would be function of stimulus (stimulus-driven attention). Moreover, a study of Evans and colleagues [60] can help us to understand why the N170 component was not always modulated by the global/local selective attention. They found greater N170 amplitude for global attention than for the local one but only when distractor elements (e.g. local elements during a global task) were invariant in the block of stimuli, in other words when distractor elements were repeated. Thus, it is possible that the enhanced negativity for frequent words would be due to specific global/holistic processing. According to the preceding authors, this greater amplitude could be interpreted in terms of a larger attentional window in the global processing than in the local one.

Usually, the global/local processing are associated to the right/left hemispheres, respectively [60-62]. However, Fink and colleagues [63] observed an effect of stimulus category on hemispheric specialization for global and local processing. Because of the well-known left hemisphere specialization and advantage in word processing, this leftward asymmetric effect seems consistent with our global interpretation. Indeed the hemisphere that is specialized in the word recognition is the more likely to engage fast global/holistic processing. It is also in agreement with the hemifield presentation study of Lavidor and colleagues [64] which suggested that the left hemisphere has a greater sensitivity to words presented in a familiar format. The development of such a sensitivity is due to the continuous exposure to written words and at the end only the left hemisphere recognizes words by direct addressing to lexicon (see also [28]).

\section{Expertise effects}

Because some left occipito-temporal areas may be specialized in visual word recognition and orthographic skills
[65], the repetition of invariant perceptive elements may improve the level of expertise of the subjects or increase the level of familiarity and thereby generating greater activities at this location. One study reported a significant interaction on the N170 amplitude evoked by birds and dogs and the level of expertise of a group of participants that included bird watchers and dog breeders [47]. When the subjects attained a high level of expertise, the N170 amplitude was larger, suggestive of a superior perceptual learning. Likewise, the level of expertise may change the manner in which the visual stimuli are processed [66]. It could then be assumed that the larger negativity during a massive repetition would be due to a "perceptual learning".

Recently two ERPs studies compared letter perception/ reading in two languages using different alphabets in mono and bilingual subjects $[67,68]$. They evidenced a larger N170 amplitude in monolingual subjects reading letterstrings in their native language in comparison to letterstrings of a foreign language using different alphabet such as Chinese or Arabic for English or French subjects respectively. On the contrary, such differences were absent in bilingual subjects. These results are in agreement with the expertise hypothesis and suggest that the subjects develop skilled process, especially in the left hemisphere, to fast recognize letters of a language for witch they have a great exposure. Our protocol contained massively repeated stimuli that permitted to simulate at a lesser extend this continuous exposure to written words during reading acquisition. As a matter of fact our results evidenced that this repetition enhances the N170 amplitude of frequent words as the expertise do. However one of the major questions that further studies would have to answer is to know if this expertise effect depends exclusively on the repetition or if the knowledge about stimuli is crucial to obtain this effect.

\section{Conclusion}

The N170 component represents a major step in the visual word recognition. The effects of the repetition, the word frequency and the word visual shape manipulation evidenced on this component suggest the existence of more than one unique way to encode a string of letters. Further studies should investigate the impact of the age of word acquisition on N170 because we can hypothesize that the holistic logographic process could depend on a critical period during the childhood. Recently, Fiebach and colleagues [69] attempted to isolate the brain areas more activated for early learned words in comparison to later ones during a visual lexical decision task and suggested that reading an early learned word actives the sound structure of this word or the semantic knowledge in a more direct way. All these data converge to the interpretation that the early acquisition of a word, its great expertise, and its high 
frequency favor the use of a more global/holistic processing of words and the present N170 amplitude increase reflects such a processing.

\section{Competing interests}

The author(s) declare that they have no competing interests.

\section{Authors' contributions}

GS elaborated stimuli, participated to EEG acquisition and post-processing, statistical analysis, redaction of the manuscript and created figures. LP participated to the redaction of the manuscript. CB created software for stimuli presentation and ERP processing. MR participated in the design of the study.

\section{Acknowledgements}

The authors are grateful to Nathalie Tzourio-Mazoyer for its precious advices. Gregory Simon was supported by a grant from the French Minister of Research.

\section{References}

I. Bentin S, Allison T, Puce A, Perez A, McCarthy G: Electrophysiological studies of face perception in humans. J Cogn Neurosci 1996, 8:55I-565.

2. Rebai M, Poiroux S, Bernard C, Lalonde R: Event-related potentials for category-specific information during passive viewing of faces and objects. Int J Neurosci 200I, I 06(3-4):209-226.

3. Rossion B, Gauthier I, Tarr MJ, Despland P, Bruyer R, Linotte S, Crommelinck M: The NI70 occipito-temporal component is delayed and enhanced to inverted faces but not to inverted objects: an electrophysiological account of face-specific processes in the human brain. Neuroreport 2000, I I (I):69-74.

4. Rossion B, Gauthier I, Goffaux V, Tarr MJ, Crommelinck M: Expertise training with novel objects leads to left-lateralized facelike electrophysiological responses. Psychol Sci 2002, I 3(3):250-257.

5. Bentin S, Golland Y: Meaningful processing of meaningless stimuli: the influence of perceptual experience on early visual processing of faces. Cognition 2002, 86(I):BI-I4.

6. Jemel B, Pisani M, Calabria M, Crommelinck M, Bruyer R: Is the NI 70 for faces cognitively penetrable? Evidence from repetition priming of Mooney faces of familiar and unfamiliar persons. Brain Res Cogn Brain Res 2003, I 7(2):431-446.

7. Rossion B, Joyce CA, Cottrell GW, Tarr MJ: Early lateralization and orientation tuning for face, word, and object processing in the visual cortex. Neuroimage 2003, 20(3): |609-I624.

8. Vigneau M, Jobard G, Mazoyer B, Tzourio-Mazoyer N: Word and non-word reading: what role for the Visual Word Form Area? Neuroimage 2005, 27(3):694-705

9. Bentin S, Mouchetant-Rostaing Y, Giard MH, Echallier JF, Pernier J: ERP manifestations of processing printed words at different psycholinguistic levels: time course and scalp distribution. J Cogn Neurosci 1999, I I (3):235-260.

10. Tarkiainen A, Helenius P, Hansen PC, Cornelissen PL, Salmelin R: Dynamics of letter string perception in the human occipitotemporal cortex. Brain I999, I 22(Pt I I):2I I9-2 I 32.

II. Simon G, Bernard C, Largy P, Lalonde R, Rebai M: Chronometry of visual word recognition during passive and lexical decision tasks: an ERP investigation. Int J Neurosci 2004, I | 4( I I): | 40 I- | 432

12. Maurer U, Brandeis D, McCandliss BD: Fast, visual specialization for reading in English revealed by the topography of the NI 70 ERP response. Behav Brain Funct 2005, I: I 3 .

13. Brem S, Bucher K, Halder P, Summers P, Dietrich T, Martin E, Brandeis $D$ : Evidence for developmental changes in the visual word processing network beyond adolescence. Neuroimage 2006, 29(3):822-837.
14. Dehaene S, Le Clec'H G, Poline JB, Le Bihan D, Cohen L: The visual word form area: a prelexical representation of visual words in the fusiform gyrus. Neuroreport 2002, I3(3):321-325.

I5. Sereno SC, Brewer CC, O'Donnell PJ: Context effects in word recognition: evidence for early interactive processing. Psychol Sci 2003, 14(4):328-333.

16. Sereno SC, Rayner K, Posner MI: Establishing a time-line of word recognition: evidence from eye movements and eventrelated potentials. Neuroreport 1998, 9(I 0):2195-2200.

17. Hauk O, Pulvermuller F: Effects of word length and frequency on the human event-related potential. Clin Neurophysiol 2004 , I I 5(5): I090-I I 03.

18. Assadollahi R, Pulvermuller F: Early influences of word length and frequency: a group study using MEG. Neuroreport 2003 , |4(8): | | 83- I | 87

19. Assadollahi R, Pulvermuller F: Neuromagnetic evidence for early access to cognitive representations. Neuroreport 2001, | 2(2):207-2| 3 .

20. Caharel S, Poiroux S, Bernard C, Thibaut F, Lalonde R, Rebai M: ERPs associated with familiarity and degree of familiarity during face recognition. Int J Neurosci 2002, I I 2(I 2): | 499-I5 I 2.

21. Caharel S, Courtay N, Bernard C, Lalonde R, Rebai M: Familiarity and emotional expression influence an early stage of face processing: an electrophysiological study. Brain Cogn 2005, 59(I):96-100.

22. Frith U: Beneath the surface of developpemental dyslexia. In Surface dyslexia Edited by: Patterson K, Coltheart M, Marshall JC. Hillsdale , Lawrence Erlbaum; 1985:301-330.

23. Aghababian V, Nazir TA, Lancon C, Tardy M: From "logographic" to normal reading: the case of a deaf beginning reader. Brain Lang 200I, 78(2):2I2-223.

24. Tarkiainen A, Cornelissen PL, Salmelin R: Dynamics of visual feature analysis and object-level processing in face versus letterstring perception. Brain 2002, I 25(Pt 5): I | 25- I I 36.

25. Perea M, Rosa E: Does "whole-word shape" play a role in visual word recognition? Percept Psychophys 2002, 64(5):785-794.

26. Mechelli A, Humphreys GW, Mayall K, Olson A, Price C): Differential effects of word length and visual contrast in the fusiform and lingual gyri during reading. Proc R Soc Lond B Biol Sci 2000 , 267(1455): 1909-1913.

27. Besner D, McCann RS: Word frequency and pattern distortion in visual word identification and production: An examination of four classes of models. In Attention and Performance Volume XII. Edited by: Coltheart M. London, Erlbaum; 1987:201-219.

28. Lavidor $M$, Ellis AW, Pansky $A$ : Case alternation and length effects in lateralized word recognition: Studies of English and Hebrew. Brain Cogn 2002, 50(2):257-27I.

29. Mayall K, Humphreys GW: Case mixing and the task sensitive disruption of lexical processing. J Exp Psychol Learn Mem Cogn 1996, 22:278-294.

30. Mayall K, Humphreys GW, Mechelli A, Olson A, Price Cl: The effects of case mixing on word recognition: evidence from a PET study. J Cogn Neurosci 200I, I3(6):844-853.

31. Polk TA, Farah MJ: Functional MRI evidence for an abstract, not perceptual, word-form area. J Exp Psychol Gen 2002, I 3 I ( I):65-72

32. Oldfield RC: The assessment and analysis of handedness: the Edinburgh inventory. Neuropsychologia 1971, 9(1):97-I I3.

33. Content A, Mousty $P$, Radeau M: Brulex: une base de données lexicales informatisées pour le français écrit et parlé. L'Année Psychologique 1990, 90:551-566.

34. Bertrand $\mathrm{O}$, Perrin F, Pernier J: A theoretical justification of the average reference in topographic evoked potential studies. Electroencephalogr Clin Neurophysiol 1985, 62(6):462-464.

35. Segui J, Mehler J, Frauenfelder U, Morton J: The word frequency effect and lexical access. Neuropsychologia 1982, 20(6):6 I 5-627.

36. Balota DA, Chumbley Jl: Are lexical decisions a good measure of lexical access? The role of word frequency in the neglected decision stage. J Exp Psychol Hum Percept Perform 1984, I0(3):340-357.

37. Rugg MD: Event-related brain potentials dissociate repetition effects of high- and low-frequency words. Mem Cognit 1990, I 8(4):367-379.

38. Wagner AD, Desmond JE, Demb JB, Glover GH, Gabrieli JDE: Semantic repetition priming for verbal and pictorial knowl- 
edge : A functional MRI study of left inferior prefrontal cortex. J Cogn Neurosci 1997, 9(6):714-726.

39. Henson RN, Shallice T, Gorno-Tempini ML, Dolan RJ: Face repetition effects in implicit and explicit memory tests as measured by fMRI. Cereb Cortex 2002, I 2(2): 178-186.

40. Dhond RP, Buckner RL, Dale AM, Marinkovic K, Halgren E: Spatiotemporal maps of brain activity underlying word generation and their modification during repetition priming. J Neurosci 200I, 2 I ( I 0):3564-357I.

4I. Kim M, Kim J, Kwon JS: The effect of immediate and delayed word repetition on event-related potential in a continuous recognition task. Brain Res Cogn Brain Res 200I, I I(3):387-396.

42. Rugg MD: The effects of semantic priming and word repetition on event-related potentials. Psychophysiology 1985, 22:642647.

43. Rugg MD: Dissociation of semantic priming, word and nonword repetion effects by Event-Related Potentials. Q J Exp Psychol A 1987, 39: 123-I48.

44. Bentin S, McCarthy G: The effects of immediate stimulus repetition on reaction time and Event-related Potentials in tasks of different complexity. J Exp Psychol Learn Mem Cogn 1994, 20(I): 130-149.

45. Dhond RP, Witzel T, Dale AM, Halgren E: Spatiotemporal brain maps of delayed word repetition and recognition. Neuroimage 2005, 28(2):293-304.

46. Dehaene S, Naccache L, Cohen L, Bihan DL, Mangin JF, Poline JB, Riviere D: Cerebral mechanisms of word masking and unconscious repetition priming. Nat Neurosci 200I, 4(7):752-758.

47. Tanaka JW, Curran T: A neural basis for expert object recognition. Psychol Sci 200I, I 2(I):43-47.

48. Coltheart M, Rastle K, Perry C, Langdon R, Ziegler J: DRC: a dua route cascaded model of visual word recognition and reading aloud. Psychol Rev 200I, 108(I):204-256.

49. Jobard G, Crivello F, Tzourio-Mazoyer N: Evaluation of the dual route theory of reading: a metanalysis of $\mathbf{3 5}$ neuroimaging studies. Neuroimage 2003, 20(2):693-7/2.

50. Allen PA, Wallace B, Weber TA: Influence of case type, word frequency, and exposure duration on visual word recognition. J Exp Psychol Hum Percept Perform 1995, 2 I(4):914-934.

5I. Torriente I, Valdes-Sosa M, Ramirez D, Bobes MA: Visual evoked potentials related to motion-onset are modulated by attention. Vision Res 1999, 39(24):4122-4139.

52. Ramus F, Rosen S, Dakin SC, Day BL, Castellote JM, White S, Frith U: Theories of developmental dyslexia: insights from a multiple case study of dyslexic adults. Brain 2003, I 26(Pt 4):84I-865.

53. Vidyasagar TR: A neuronal model of attentional spotlight: parietal guiding the temporal. Brain Res Brain Res Rev 1999, 30(I):66-76

54. Han S, He X, Woods DL: Hierarchical processing and level-repetition effect as indexed by early brain potentials. Psychophysiology 2000, 37(6):8I7-830.

55. Jiang Y, Han S: Neural mechanisms of global/local processing of bilateral visual inputs: an ERP study. Clin Neurophysiol 2005, I I 6(6): I 444-I 454.

56. Volberg G, Hubner $\mathrm{R}$ : On the role of response conflicts and stimulus position for hemispheric differences in global/local processing: an ERP study. Neuropsychologia 2004, 42(13): $1805-1813$.

57. Yamaguchi S, Yamagata S, Kobayashi S: Cerebral asymmetry of the "top-down" allocation of attention to global and local features. J Neurosci 2000, 20(9):RC72.

58. Han S, Liu W, Yund EW, Woods DL: Interactions between spatial attention and global/local feature selection: an ERP study. Neuroreport 2000, I I(I 2):2753-2758.

59. Han S, Yund EW, Woods DL: An ERP study of the global precedence effect: the role of spatial frequency. Clin Neurophysio 2003, I I 4(I 0): 1850- I 865.

60. Evans MA, Shedden JM, Hevenor SJ, Hahn MC: The effect of variability of unattended information on global and local processing: evidence for lateralization at early stages of processing. Neuropsychologia 2000, 38(3):225-239.

6I. Fink GR, Halligan PW, Marshall JC, Frith CD, Frackowiak RS, Dolan $\mathrm{RJ}$ : Where in the brain does visual attention select the forest and the trees? Nature 1996, 382(6592):626-628.
62. Moses P, Roe K, Buxton RB, Wong EC, Frank LR, Stiles J: Functional MRI of global and local processing in children. Neuroimage 2002, 16(2):4I5-424.

63. Fink GR, Marshall JC, Halligan PW, Frith CD, Frackowiak RS, Dolan $\mathrm{RJ}$ : Hemispheric specialization for global and local processing: the effect of stimulus category. Proc Biol Sci 1997 264( I 38 I ):487-494.

64. Lavidor M, Babkoff H, Faust M: Analysis of standard and nonstandard visual word format in the two hemispheres. Neuropsychologia 200I, 39(4):430-439.

65. McCandliss BD, Cohen L, Dehaene S: The visual word form area: expertise for reading in the fusiform gyrus. Trends Cogn $\mathrm{Sci}$ 2003, 7(7):293-299.

66. Carmel D, Bentin S: Domain specificity versus expertise: factors influencing distinct processing of faces. Cognition 2002, 83(I): I-29.

67. Wong AC, Gauthier I, Woroch B, DeBuse C, Curran T: An early electrophysiological response associated with expertise in letter perception. Cogn Affect Behav Neurosci 2005, 5(3):306-3I8.

68. Simon G, Bernard C, Lalonde R, Rebai M: Orthographic transparency and grapheme-phoneme conversion: An ERP study in Arabic and French readers. Brain Res 2006, I I 04(I): | $4 \mid-152$.

69. Fiebach CJ, Friederici AD, Muller K, von Cramon DY, Hernandez AE: Distinct brain representations for early and late learned words. Neuroimage 2003, 19(4):1627-1637.

Publish with Bio Med Central and every scientist can read your work free of charge

"BioMed Central will be the most significant development for disseminating the results of biomedical research in our lifetime. "

Sir Paul Nurse, Cancer Research UK

Your research papers will be:

- available free of charge to the entire biomedical community

- peer reviewed and published immediately upon acceptance

- cited in PubMed and archived on PubMed Central

- yours - you keep the copyright 